\section{FRI0247 COMPARISON OF THE RITUXIMAB(RTM) IN MONOTHERAPY REGIMEN AND MYCOPHENOLATE MOFETIL (MMF) EFFICACY AND SAFETY IN SYSTEMIC SCLEROSIS (SSC) WITH INTERSTITIAL LUNG DISEASE (ILD)}

O. Koneva ${ }^{1}$, L. Ananieva ${ }^{1}$, L. Garzanova ${ }^{1}$, O. Desinova ${ }^{1}$, O. Ovsyannikova ${ }^{1}$, M. Starovoytova ${ }^{1}{ }^{1}$ V.A. Nasonova Research Institute of Rheumatology, Moscow, Russian Federation

Background: Although ILD occurs in the majority of patients with SSc, treatment options for this manifestation is empirical and at present consists of cyclophosphamide or MMF. However, the immunosuppressants(IS) use leads to rather limited improvement of ILD and is associated with many adverse reactions. The search for novel, more efficacious agents has been continued, such as attracting much attention RTM.

Objectives: To compare the impact of MMF and RTM a single-agent therapy on SSc clinical manifestation and activity, and the safety of these agents in the open-label prospective non-randomized study.

Methods: 80 patients with the confirmed SSc diagnosis and ILD evidence based on MSCT findings were enrolled into the study. All patients received low and moderate-dose glucocorticoids regimens. Group $A(n=35)$ received RTM as a single therapy agent for $13.3 \pm 2.3$ months at total dose $1.35 \pm 0,5 \mathrm{~g}$ (the patient's average age was $45.0 \pm 15$ years, with female proportion $80 \%$; SSc duration $6.3 \pm 2.3$ years; diffused/localized forms $1.3 / 1)$. Group $B(n=36)$ received MMF for $12 \pm 6$ months at total dose $10.6 \pm 5 \mathrm{~g}$ (the average age $49 \pm 13$ years, females $91 \%$, SSc duration $7.1 \pm 5$ years, diffused/localized forms $1 / 1.3$ ). The time courses of FVC, DLCO, modified skin count(mRss, points), activity index (EScSG, points), and cardiac rhythm and conductivity disorders(ECG) were assessed into the study.

Results: In Groups $A$ and $B$ the therapy was associated with significant decrease in $\mathrm{mRss}(\mathrm{p}=0.02$ and 0.009 , respectively) and $\mathrm{EScSG}(\mathrm{p}=0.00017$ and 0.000165 , respectively). Reducing the number of patients with cardiac conductivity disorders was observed only in MMF-treated patients $(p=0.03)$.

Evaluation of FVC time course revealed significant FVC increase only in Group $A(p=0.002)$, with median increment about $5 \%$.

In Group A 10\% FVC increase was found in the third of the patients thus exceeding respective parameter in Group $B(p=0.2)$. The patient percentage with $F V C$ decrease by $\geq 10 \%$ did not differ significantly between groups.

During the follow-up period no change of the other studied parameters was observed.

The therapy was better tolerated in RTM-treated group: during RTM therapy adverse reactions emerged in lower proportion of the patients(4/11\%) compared with MMF-treated group(12/27\%), $\mathrm{p}=0,5$.

\begin{tabular}{lcc}
\hline Parameters & Group A & Group B \\
\hline Activity Index1 $M \pm S D$ & $2.8 \pm 1.4^{*}$ & $1.9 \pm 1.5^{*}$ \\
Activity Index2 $M \pm S D$ & $1.4 \pm 1.2^{*}$ & $1.2 \pm 0.9^{*}$ \\
Skin count $M \pm S D$ & $11.5 \pm 9.5^{*}$ & $7.5 \pm 6.9^{*}$ \\
Skin count2 $M \pm S D$ & $8.2 \pm 6.2^{*}$ & $4.8 \pm 3.9^{*}$ \\
FVC1 $M \pm S D$ & $78.7 \pm 20.0^{*}$ & $90.3 \pm 20.8$ \\
FVC2 $M \pm S D$ & $84.2 \pm 20.0^{*}$ & $92.2 \pm 21.0$ \\
$\Delta F V C \%$ & $5.3[0.8 ; 11.1]$ & $1.9[-3.5 ; 6.0]$ \\
FVC increment by $\geq 10 \%, \mathrm{n} / \%$ & $9 / 26$ & $6 / 13.3$ \\
FVC decrement by $\geq 10 \% \mathrm{n} / \%$ & $2 / 5.7$ & $4 / 8.9$ \\
DLCO1 $M \pm S D$ & $51.8 \pm 19.9$ & $52.2 \pm 17.4$ \\
DLCO2 $M \pm S D$ & $49.5 \pm 16.0$ & $51.9 \pm 17.0$ \\
$\Delta D L C O \%$ & $0.5[-4.5 ; 8.8]$ & $-1.15[-6.6 ; 3,65]$ \\
DLCO increment by $\geq 10 \%, \mathrm{n} / \%$ & $3 / 8.6$ & $4 / 8.9$ \\
DLCO decrement by $\geq 10 \% \mathrm{n} / \%$ & $3 / 8,6$ & $6 / 13.3$ \\
number of patients with cardiac conductivity & $13 / 37$ & $13 / 29^{*}$ \\
disorders1, $\mathrm{n} / \%$ & & \\
number of patients with cardiac conductivity & $14 / 40$ & $5 / 11^{*}$ \\
disorders2, $\mathrm{n} / \%$ & &
\end{tabular}

Notes: in Parameters column 1 = before treatment, 2 = after treatment; $\mathrm{M} \pm \mathrm{SD}=$ mean value and standard deviation; ${ }^{*}=$ significant difference between the vales measured before and after the treatment

Conclusion: Both agents effectively alleviated skin induration and EScSG, and significantly improved FVC. However, only RTM use revealed significant FVC increase including clinically significant FVC increase. RTM was slightly better tolerated compared to MMF. The study findings substantiate potential use of RTM both as a first-line agent for ILD treatment in the patients with SSc, and in the event of IS inefficacy of poor tolerability. The MMF use is more preferable in patients with less pronounced ILD and cardiopathy.

Disclosure of Interests: None declared

DOI: 10.1136/annrheumdis-2020-eular.4235

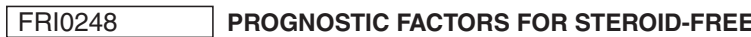 REMISSION IN PATIENTS WITH IDIOPATHIC INFLAMMATORY MYOPATHIES: IMPORTANCE OF ANTHROPOMETRIC MEASUREMENTS}

J. S. Lee ${ }^{1}$, S. H. Nam ${ }^{1}$, S. J. Choi ${ }^{1}$, W. J. Seo ${ }^{2}$, S. Hong ${ }^{1}$, C. K. Lee ${ }^{1}$, B. Yoo ${ }^{1}$, J. S. $\mathrm{Oh}^{3}$, Y. G. Kim ${ }^{1}{ }^{1}$ University of Ulsan College of Medicine, Asan Medical Center, Division of Rheumatology, Department of Internal Medicine, Seoul, Korea, Rep. of (South Korea); ${ }^{2}$ Seoul Veterans Hospital, Division of Rheumatology, Department of Internal Medicine, Seoul, Korea, Rep. of (South Korea); ${ }^{3}$ Asan Medical Center, Department of Biomedical Informatics, Seoul, Korea, Rep. of (South Korea)

Background: Several studies have been conducted on factors associated with mortality in idiopathic inflammatory myopathies (IIM), but few studies have assessed prognostic factors for steroid-free remission in IIM.

Objectives: We investigated the various clinical factors, including body measurements, that affect IIM treatment outcomes.

Methods: Patients who were newly diagnosed with IIM between 2000 and 2018 were included. Steroid-free remission was defined as at least three months of normalisation of muscle enzymes and no detectable clinical disease activity. The factors associated with steroid-free remission were evaluated by a Cox regression analysis.

Results: Of the 106 IIM patients, 35 displayed steroid-free remission during follow-up periods. In the multivariable Cox regression analyses, immunosuppres sants' early use within one month after diagnosis [hazard ratio (HR) 6.21, 95\% confidence interval $(\mathrm{Cl}) 2.61-14.74, \mathrm{p}<0.001$ ] and sex-specific height quartiles (second and third quartiles versus first quartile, HR 3.65, 95\% Cl 1.40-9.51, p = 0.008 and $\mathrm{HR} 2.88,95 \% \mathrm{Cl} 1.13-7.32, \mathrm{p}=0.027$, respectively) were positively associated with steroid-free remission. Polymyositis versus dermatomyositis (HR 0.21, 95\% Cl 0.09-0.53, p = 0.001), presence of dysphagia (HR 0.15, C $0.05-0.50, p=0.002$ ) and highest versus lowest quartile of waist circumference (WC) (HR $0.24,95 \% \mathrm{Cl} 0.07-0.85, \mathrm{p}=0.027$ ) were negatively associated with steroid-free remission.

Conclusion: The early initiation of immunosuppressant therapy, type of myositis and presence of dysphagia are strong predictors of steroid-free remission in IIM; moreover, height and WC measurements at baseline may provide additional important prognostic value.

Disclosure of Interests: None declared

DOI: 10.1136/annrheumdis-2020-eular.3010

FRI0249 IN MYOSITIS PATIENTS, SJÖGREN'S SYNDROME IS ASSOCIATED WITH INCLUSION BODY MYOSITIS AND WITH ANTI-CN1A ANTIBODIES INDEPENDENTLY OF THE MYOSITIS SUBTYPE

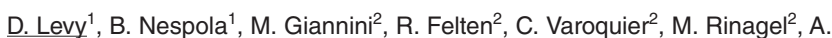
S. Korganow ${ }^{2}$, V. Poindron ${ }^{2}$, T. Martin ${ }^{2}$, F. Maurier ${ }^{3}$, H. Chereih ${ }^{4}$, B. Bouldoires ${ }^{5}$, B. Hervier ${ }^{6}$, C. Lenormand ${ }^{2}$, L. Arnaud ${ }^{1}$, B. Geny ${ }^{1}$, J. Sibilia ${ }^{1}$, J. E. Gottenberg ${ }^{1}$, A. Meyer ${ }^{1} .{ }^{1}$ Strasbourg, Strasbourg, France; ${ }^{2}$ Hôpitaux Universitaires,

Strasbourg, France; ${ }^{3}$ Hôpital Privé, Metz, France; ${ }^{4}$ Pontarlier, Pontarlier, France; ${ }^{5}$ Colmar, Colmar, France; ${ }^{6}$ Paris, Paris, France

Background: Myositis are characterized by weakness and muscle inflammation. They encompass heterogeneous conditions, which include dermatomyositis (DM), inclusion body myositis (IBM) and polymyositis (PM) according to the EULAR/ACR 2017 criteria. We recently recorded a high prevalence of IBM in a cohort of primary Sjögren's syndrome (SS) (1). The signification of SS in the setting of myositis is unanswered.

Objectives: To refine the signification of SS in the setting of myositis.

Methods: Among a monocentric myositis cohort (according to the EULAR/ACR 2017 criteria), SS patients (according to the ACR/EULAR 2016 criteria) were identified (myositis/SS+ group) and compared to myositis patients without SS (myositis/SS- group)

Results: Among 414 myositis patients, SS criteria were available for 96 patients. Thirty two (33\%) presented SS. Patients with SS tended to be more frequently women ( $F / M$ ratio 9.7 vs $3.0, p=0.07)$. Age at diagnosis of myositis was similar in both groups (53 years [range 21-74] vs 53 years [range 16-77], $p=0.51$ ).

Myositis subtypes repartition (as defined by EULAR/ACR 2017 criteria) was different in myositis/SS+ and myositis/SS- groups $(p=0.021)$, IBM being four-fold more prevalent in myositis/SS+ group ( $25 \%$ vs $6 \%, p=0.018)$. Accordingly, the delay between the first muscle symptoms and myositis diagnosis was longer in myositis/SS+ group (7 months [0-336] vs 4 months [0-122], $p=0.041)$. Moreover, aside anti-cN1A antibodies, myositis-specific antibodies were less frequently found in myositis/SS+ patients than in myositis/SS- ones (16/32 [50\%] vs $46 / 64$ $[72 \%], p=0.035)$ 